\title{
Reference and Countermeasure of PPP Model Legislation
}

\author{
Chunxue Fan
}

Beihua University Law School,no.3999, hua shan road, jilin city,jilin province,China

fanchunxue_beihua@163.com

Keywords: PPP model; Legislation; Legislative system; Reference and countermeasures

\begin{abstract}
The PPP model is a product of continuous development in today's era and plays a key role in various fields. However, its development depends on the improvement of legislation. This paper has obtained beneficial inspiration from the research on the legislation of various countries' PPP models and combined with our country's with regard to the current status of the use of the PPP model, starting from the actual situation, aiming at the existing problems in China's legislation, and put forward a reasonable countermeasure for China's relevant legislative models.

The PPP (Public Private Partnership) model is a public infrastructure construction model in which the public and private partners form a good partnership. The PPP model serves as a link between the public sector and the private sector. Perfecting the legal system is the most powerful guarantee for ensuring the normal implementation of the PPP model in the country.

The implementation of the PPP model in China has just started and there are obvious deficiencies in its legislation. The content of existing laws and regulations cannot effectively guarantee the development of the PPP model, and it lacks the necessary laws to involve the private sector in the infrastructure construction and operation. Regulations and detailed operating procedures. However, in many countries in the world, such as the United Kingdom, the United States, Japan, and South Korea, the PPP model establishes and perfects clear laws and regulations based on national conditions to ensure that the PPP model is maximized in the country. Therefore, in the face of the current status of the PPP model, China has explored the relevant laws and regulations for the PPP model that suits China's development against the existing successful experience abroad, and promoted the development of the PPP model in China.
\end{abstract}

\section{The Necessity of Perfecting the PPP Model Legal System}

Promoting the Development of Public Utilities. With the rapid development of the times, public utilities have received increasing attention from government departments and the close attention of community residents. As a result, the quality of public services and public goods has been improved, a PPP model has emerged, and the development of public utilities in China has been promoted. The PPP model has the advantages of public-wealth purposes of the public sector public utilities and funds of the private capital of the society, and it combines these advantages to expand the development channels of the public utilities to unlimited possibilities and improve the professionalism and stability of the public utilities. At the same time, the quality of the public service has been improved under the constraints and incentives of the market mechanism. Therefore, the public utility is of great significance to the PPP model. It is the starting point and the end result.

The ultimate meaning of realizing the development of public utilities. Therefore, China's laws and regulations for the PPP model should be improved as soon as possible. The laws and regulations of the PPP model clarify the supervision and management of government departments and community residents, as well as the rights and obligations of both participants, and promote the application and popularization of the PPP model, and ultimately promote the development of the public service.

Accelerate the Realization of the Transformation of Government Functions. Based on the basic viewpoint of "social contract theory", our country makes public services and public goods the center and focus of government functions. The implementation of the PPP model will provide new ideas for the government's public sector to achieve service government transformation goals, and in the construction of service-oriented government, the scope of the government's public service 
functions will be expanded. At the same time, the characteristics of the new public sector will be based on the past. The government model does not meet the development needs, thereby introducing the power of social private capital to enable the government to perform public service functions.

Accelerating the transformation of government functions, China's laws and regulations for the PPP model have been rapidly improved, making the PPP model more operational, standardized, and the government's supervision and management more clear and accurate, and improving government departments' enthusiasm for public services. Speed up the realization of the transformation of government functions.

Promoting the Development of Economic Stability and Progress. Our country's economic development policy is "steady progress." Its contents include the rapid development of public utilities and the rapid transformation of government functions. The promotion of the development of the PPP model has prompted China's public services and private capital to participate in public utilities to obtain a huge return on investment. At the same time, it has opened up the road of social capital development, increased the return on investment of social capital, and thus promoted China's rapid economic development.

This shows that we must constantly improve both quality and quantity in our economy as a whole. China's laws and regulations for the PPP model have been rapidly improved to ensure that the PPP model is active and stable in the country's economic development. This will make our country's economic development on the road of active and stable development. At the same time, based on the economic development policy, it is "steady progress," achieving both quality and quantity.

\section{The Status of PPP Mode Regulation and Foreign Experience}

The PPP model has been implemented in China for a short time and the laws and regulations have not been perfected. There are no specific laws and regulations on the specific issues of the PPP model, and many problems have not been solved. The conflict between the spirit of buffering contract and government management has increased.

Current Status of Relevant laws and Regulations of Domestic PPP Mode. In the legal provisions, the PPP model, the standards of the use of PPP projects, the application of the methods and procedures used, etc., and there is no definitive specification, even if China has a set of laws to regulate the government procurement behavior system, but a series of laws such as the government procurement law still Many need to modify the added aspects. In the issue of legislation, the main issues of debate in the academic community are the orientation of the government's role and the particularity of the project.

The nature of the project itself is constrained. In the process of combining the public sector with the private sector, the PPP model has obvious deficiencies in its operation, including a huge amount of investment, low cooperation efficiency, and complicated implementation process. For the increasingly active application of the PPP model, certain laws and regulations in the "Government Procurement Law" and the "Bid Invitation and Bidding Law" that provide certain guidance and control functions still require a law to restrict the rapid and changeable development of the PPP model.

The role of government. Under the development of the PPP model, the government assumes the role of public sector collaborators and also serves as the regulator's adjudicator. Therefore, it has the principal privilege. During the implementation of the PPP model, the administrative subject redefined the public interest and improved its content. And so on, the government exercises the relevant privilege and then supervises and revise the contract to ensure the legitimate rights of the government and related departments. However, in the legal aspect, the non-government subject power is not clearly stipulated, resulting in the non-government entity being extremely risky in its implementation model, and thus cannot guarantee the fair and coordinated implementation of the PPP model.

For the diversity and complexity of PPP projects, the current law exposes many defects. 
Although the law has certain restrictions on the PPP project and management plans. For example, the "Government Procurement Law" and the "Implementation Regulations for the Investment Bidding Law" have a series of laws that have restrictions and management plans. However, the contents of their explanations are obviously different. The main principles and methods of the Government Procurement Law for government procurement, etc. On the other hand, there are direct provisions for supervision and inspection and legal responsibilities. It is a law that directly regulates government procurement; the bidding behavior in the "Government Procurement Law" requires the cooperation of the "Investment Bidding Law."

To ensure that the non-public economy and the private sector enter the infrastructure and public utilities sector, the Chinese Constitution stipulates: "The state protects the legitimate power and interests of the private economy, the private economy, and other non-public sectors of the economy. The state encourages, supports, and guides the development of the non-public economy." Under the guidance of the constitution, relevant state departments have formulated relevant laws and regulations, including legislative bodies and related departments of the State Council, to formulate relevant policies and regulations to ensure the smooth implementation of the PPP model in public projects. However, the above policy guidelines are not universal and merely promote the development of its own PPP model.

Foreign Related Legislative Status. PPP projects have achieved good economic benefits in the development of countries around the world, but the issue of public welfare has become increasingly difficult to guarantee as prices have risen. Hegel once said that when practice has completed its stage of development and become a problem, it began to reflect it theoretically. PPP's trust in countries such as the United States and the United States has declined. This has led governments to adjust PPP policies.

In response to the PPP model, the United Kingdom took the government's regulatory legislation as a priority to conduct private reforms. The law was used as a basis to plan and implement the PPP model process. As of 2012, the United Kingdom has provided explicit regulations on the interests, contradictions, and other issues concerning the PPP model, which has made the PPP model more effective. The United States has established a committee on the PPP model and combined it with the actual situation to give full play to the advantages of the committee. To standardize the management of relevant members, select and appoint relevant posts according to the views of the president, formulate detailed laws and regulations, and in accordance with their own actual development conditions, promulgate corresponding institutional guidelines in order to make the PPP model more promising in the United States; Regarding the PPP model, Japan established the PFI Committee, and through cooperation with local governments, it has further promoted the development of the PFI Committee in many aspects, such as risk-avoidance programs, etc., to ensure smooth operation of the PPP model; and South Korea The operation of the PPP model project is mainly through the establishment of the PPP evaluation committee to manage the PPP model accordingly. By 2005, South Korea had formulated a relatively comprehensive set of legal documents for the PPP model and established PIMAC. Its task is to establish the direction of the PPP model, and to rectify content, so as to lay a solid foundation for the smooth operation of the PPP project.

\section{The PPP Model of International Experience for Reference}

In contrast to the above countries that are more prominent in the legislation and supervision of the PPP model, the relevant laws of the PPP model in China should be strengthened as follows:

Establishing Leading Institutions. In the implementation process of the PPP model, the content involved is extensive. The operation of the PPP model needs to rely on legal support. Therefore, the legal issue of the PPP model is particularly important. At the same time, when the PPP model is in operation, it involves a very wide range of departments and departments cooperate with each other in the process. It has not been actually implemented, and therefore it has led to the actual encounter of special circumstances, the coordination between departments is not smooth, the operation tends to induce each other and unclear status.

A clear lead agency is the direction to implement the PPP model. Among the leading agencies 
that have established successful countries in the world, the United States is the most prominent one. It needs to establish a lead agency based on its own national conditions, and formulate guidelines and related policies for implementing the PPP model at the same time. At the same time, it will actively support the development of the PPP model and related supervision and guidance, and provide protection to the PPP model.

Establishing applicable laws. Establish targeted laws. The PPP model itself has a wide range of types and involves a large number of related departments, resulting in the face of special problems in the implementation of the PPP model, and the existing open legal architecture has been resolved. Therefore, the specific legislation for the PPP model has yet to be developed, so that it will be subject to restrictions on the implementation of the mode of control, ruling, etc., and ultimately the integrity of the PPP project management, so as to protect the PPP implementation of the relevant parties and the rights and interests of the country

Due to the characteristics of the legislation, in the face of the actual situation of the PPP model, the items included in the PPP model are collected and summarized quickly and efficiently. In addition, the specific types of projects are analyzed, the same category is divided into one category and relevant laws and regulations are discussed, and the solvable ideas and countermeasures are sought from laws and regulations; if the provisions of the existing laws and regulations are not yet complete, they should be based on the same type. Cases were collated and modified accordingly. Finally, the Supreme People's Court gave legal explanations, accumulated cases, summarized the basis for handling projects of the same type, accelerated the rate of legislation, and established separate laws in the name of the National People's Congress or its standing committee. We will make appropriate amendments to other legal provisions, conduct inspections in the implementation of the PPP model, and formulate laws and regulations that suit the development of China's PPP model.

Establish a law of unity. For the PPP model law, Japan and South Korea and other countries have adopted the national unified legislation model. The country's confidence and determination in the PPP model emerged, while providing investors with the most basic legal protection. Under the current legal environment in China, the PPP model legislation should be unified throughout the country. Problems such as preventing confusion and building investor confidence have emerged.

In order to effectively supplement the unified legislation, one-way legislation and local regulations were implemented. Compared with national legislation, the one-way calendar was more targeted, and the project and the region were adjusted on the basis of national legislation, and they were strongly in line with the development at that time. In order to develop PPP well, local governments should have a certain degree of enthusiasm and autonomy to adjust for real-time situations. The unified legislation solves a series of macro-level issues such as taxation, various risk-taking, company establishment, project supervision and management, and resolution of economic disputes for individual legislation; the effective level of individual legislation is relatively low, but unified legislation can be resolved in this regard.

Compared with government and private capital, the PPP model is even better, and the Chinese government still has obvious deficiencies in implementing the PPP model. In particular, as a participant, it does not consider comprehensively the interests and risks, and lacks definite policy support. Therefore, it is urgent for the government to take the initiative to guide citizens and maximizing the development of the PPP model should support the establishment of policies, establish corresponding risk-taking agencies, increase the credibility of the government, and greatly limit the attraction of non-governmental forces to ease the government's economic situation. The treatment is unified legislation.

In order to promote the smooth development of the PPP model, responding to the PPP legislation and effective supervision and management will be conducive to the effective circulation of public and private capital, activate the market, and bring about a new round of development for China's construction. Through foreign precedents, combined with market mechanisms with Chinese characteristics, and through the combination of rich practical experience and theoretical systems, we will push economic development to new areas and move toward new heights. 


\section{References}

[1] P.C. Gong and GQ. Xie: The transaction structure, legal risks and their responses to the PPP model [J]. Economic System Reform, 2016 (03).

[2] W. Liu: Theoretical Explanation of PPP Model and its Realistic Illustration [J]. Fiscal revenue and capital market, 2015(01).

[3] Y.J. Jun, Y.X.Ji and Y.Q. Yan: An Overview of International PPP Legal Policies [J]. Chinese Government Procurement, 2015(10).

[4] H.Y. Fu: Research on the Legal Issues of PPP in the United States [J].Financial Research, 2015(12).

[5] L. Wang: Administrative payment of China's natural disasters under payment administration [J]. Hebei Law Science, 2011(03):25-26.

[6] Y.Z. Yan: The double-level theory of German administrative law [J]. Global Law Review, 2015(01): 17-16.

[7] Peng L, Xiaoping Z. Social Stratification and Cooperative Behavior in Spatial Prisoners' Dilemma Games [J]. PLOS ONE, 2015, 10(7): e0131005. 